\title{
Epistemological difficulties in implementing a teaching-learning sequence on the concept of mass
}

\author{
Fabiana B. Kneubil*10 \\ ${ }^{1}$ Instituto Educacional Futuro da Ciência, São Paulo, SP, Brasil
}

Received on November 20, 2018; Revised on April 12, 2018; Accepted on August 09, 2019.

\begin{abstract}
In this work, we show the results from a research made in a curricular innovation situation, whose main focus was to assess the performance of a teacher which implemented a teaching sequence on the concept of mass. This process began by a revision of the concept of mass in three different frameworks, namely classical mechanics, electromagnetism and relativity, with the purpose of addressing the epistemological changes of the subject from Newtonian mechanics to relativity. This revision yielded a written material about the theme and was employed in the development of the teaching sequence, which had as main methodology the Design Based Research. Our main research focus concerns the performance of the implementer teacher and his appropriation of the underlying didactic intention. In order to assess how effectively this teacher did absorb the intentions of the course he delivered, we relied on Chevallard's Didactic Transposition Theory. Data were extracted from recordings of the teacher's classes and the subsequent analysis has shown that there may be a relation between the difficulties he had in conveying the didactic intention and the innovative character of the contents involved. Our results indicate that these difficulties are directly related with the very nature of scientific knowledge and, in fact, belong to the realm of epistemology.
\end{abstract}

Keywords: didactic transposition, teaching-learning sequence, teaching relativity, mass-energy equivalence, epistemology.

\section{Introduction}

Research on curriculum innovation is recurrent in science education. In Brazil, particularly, several researchers have discussed the problems of inserting modern physics into high schools and efforts were directed mostly to the development of methodologies and strategies, aimed at improving approaches to innovative contents. Since the 1980s, these studies have emphasized a need for curriculum changes, so as to incorporate both modern scientific theories and their worldviews, especially relativity and quantum mechanics, into education [1-5]. The need for changes is made urgent by the fact that technological developments, based on scientific knowledge developed along the twentieth century, are continuously transforming society and, thus, press for modifications in education. In physics education, research has often an interventionist character, with the purpose of developing teaching strategies for modern topics. At University of São Paulo, there is a group called Research Nucleus in Curricular Innovation (NUPIC), composed by researchers, lecturers, and post-graduate students which, in the last decade, has been developing didactic materials on modern physics to be introduced into public schools. The NUPIC project is focused on high school teachers and develops strategies

* Correspondence email address: fkneubil@gmail.com aimed at inserting innovative topics into the classroom [6-10].

The research presented in this paper is part of NUPIC's project and deals with a teaching-learning sequence (TLS) based on the Design-Based Research (DBR) methodology, addressing specifically the concept of mass. This concept was discussed within three different frameworks, namely those of classical mechanics, electromagnetism, and relativity, spanning three centuries of scientific development, from Newton to Einstein. Strong emphasis was given to both conceptual and epistemological changes. A teacher was invited to participate in the design process and also to deliver the ensuing course, which was aimed at practicing high school physics teachers. The analysis of the implementation process was based on the ideas of Didactic Transposition theory, by Chevallard [11], together with his concepts of didactic intention and epistemological surveillance. Our research questions, concerning the actions performed by the implementer teacher during the course and his ability to appropriate the underlying didactic intention, were framed by Chevallard's three spheres of knowledge. The classes delivered by the implementer teacher were video recorded and, using the methods of qualitative research, we observed a possible relation between the difficulties he had in conveying the didactic intention and the innovative character of the contents presented. As the teaching sequence pro- 
gressed and modern physics subjects began to appear, the difficulty the teacher had in manifesting the didactic intention increased. Our results indicate that many of these difficulties were not just technical but, rather, directly related with the nature of scientific knowledge and, therefore, associated with the acquaintance the teacher had in dealing with epistemological matters.

This paper is organized as follows: in section 2, we describe the DBR methodology in general terms and show how it was used to construct our research settings, the didactic sequence on the concept of mass and the sequence of topics approached in the TLS. In section 3 , we discuss the context of the teaching process, using Chevallard's Didactic Transposition theory, place our research questions and raise problems about the teacher's performance and his difficulties in conveying the didactic intention of the TLS. We present, in section 4, the method employed to analyze the implementer teacher's classes and to assess the didactic intention of each topic delivered in the course. In the next two sections, we present and discuss the results of our analysis, relying on both observation of his classes and comparisons with the didactic intention explicit in the teacher's guidelines developed in the design process. In section 6 , we bring some epistemological elements from Bachelard and Kuhn to frame our analysis and support the main result of our investigation. Finally, in section 7 , we present our concluding remarks.

\section{Design-Based Research}

Design-Based Research (DBR) is a set of methodologies that emerged during 1990s, based on interventionist methods and aimed at relating theoretical aspects of educational research with practice. This methodology, introduced in the education context by Brown [12] and Collins [13], was later employed by other researchers [14-15] and became a line that implements innovation in actual classroom settings. The DBR deals with the entire teaching process, starting from an innovative idea and following it up to its effective implementation.

The DBR has an interventionist character, which is rather important for promoting a link between theoretical and practical dimensions. Van den Akker [16] stresses that the relationship between theory and practice is very complex and, sometimes, the direct application of theory does not solve practical problems. This methodology has been employed in many areas of innovation. In both educational and teaching contexts, researchers and educators in science of nature uses the DBR methodology, adapting it to classroom settings, taking into account learners' initial conceptions and research results on learning. Due to the main characteristic of the process management of DBR methodology, it has been using to design, implement, and evaluate teaching-learning sequences (TLS) on specific science subjects by researcher groups [17]. They argue that general educational and learning theories may not help solving problems related to practice. According to them, theories unrelated to specific science subjects do not ensure didactical quality in teaching [18]. These authors state that 'flight away from content' promotes a gap in a didactical dimension, which is essential to promote the didactical progress. They also stress that the missing level is that of describing and understanding what is, or should be, going on in science classrooms in terms of content-specific interactions of teaching-learning processes, and of trying to interpret them in terms of didactical theory [18, p. 538].

Teaching-learning sequences encompass both actions of interventionist research and products, that include designed learning activities, empirically adapted to the reasoning of students and to classroom settings. The development of a TLS takes into account issues such as student conceptions, particularities of specific contents, epistemological assumptions, learning perspectives, pedagogical approaches, features of educational context. It was widely used in investigative research regarding cognitive learning of both students and teachers and, in the present research, the name TLS refers to an investigation guided by specific topics [19].

The Design-Based Research has already proved to be effective, since results from several implementations did produce knowledge that contributes to a didactical theory. Traditional educational theories tend not to subsidize the actions of teachers in the classroom, indicating a lack of teaching knowledge that could be applied in real contexts. Scientific school knowledge must be associated with this methodological-didactic attitude and Tiberghien [20], for instance, encourages educators and researchers to develop sequences for more challenging topics, since designing sequences for all subjects of science is unfeasible. However, as some features of scientific knowledge are general, results generated by the implementation of a given subject can be transferred to other contexts and applied by other teachers. The dealing with TLSs can provide new didactic knowledge and improve practice, even in the case of experienced teachers, for they can promote awareness about difficulties regarding certain topics, which would take a long time to be incorporated by teachers if they had to be discovered by themselves.

As a general procedure, during the design of a TLS about a specific scientific content, the researcher and the design team use to state research questions, which guide both the investigation and the process evaluation. Therefore, results of specific developments tend to be related to these questions posed previously. Some examples of didactic sequences developed using DBR-methodology can be found in [21]. They deal with a specific theme and have its own aim of implementation, which often is the improvement of the very TLS, by means of a re-design procedure. 


\subsection{Design process}

The work described in this paper does follow the TLS methodology, but has two distinctive features. One of them concerns its main target, which were high school physics teachers, instead of students, whereas the other is a focus on the difficulties found by the implementer teacher to deliver the course, instead on the refinement of TLS procedures. Special attention was paid to epistemological elements associated with the physics content considered.

Before beginning the design of our TLS, we had already written a didactic material, in collaboration with an experienced researcher in particle physics, covering the contents to be taught in reasonable detail. It is about 170 pages long, and describes the concept of mass in three different contexts, namely classical mechanics, electromagnetism, and special relativity, so as to highlight changes. Figure 1 shows the cover of this handout and the list of contents can be found in Appendix 1. This material was employed in a first version of the course, called 'Mass: the concept from Newton to Higgs', aimed at 33 high school physics teachers in an in-service teacher training program, delivered by a member of the design team, in January 2013. The purpose of this prototype course was to test both the depth and the length of the content discussed. Just after its end, two participants were invited to join the design team, so that one of them could implement our TLS with the same content.

The need of an explicit didactic intention (DI) was foremost in the design of the course of the TLS. The process of writing the supporting text was essential to fully disclosing and clarifying this DI and, eventually, it became embodied in the written handout. In particular, we took great care with the ordering of topics, so as to highlight changes in the concept of mass. In the next four months, the design team was composed by two physics teachers and a particle physicist, under the supervisor of the lead researcher, and we held 12 meetings, about 3 hours long, and all of them were audio recorded. Their main task was the discussion of contents and organization of guidelines to be used by the implementer teacher in each lesson, which included: (a) a main goal, (b) physics content,
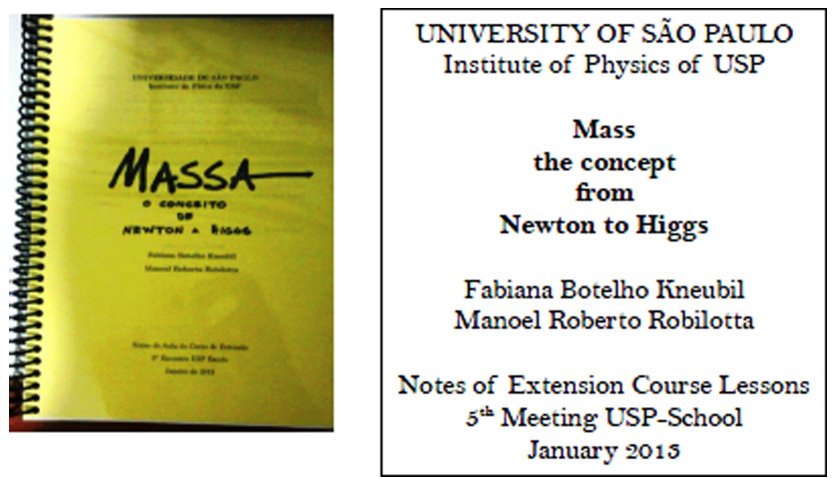

Figure 1: Handout cover (c) prerequisites needed, (d) educational resources, (e) optional suggested readings, (f) a division of contents into time blocks, (g) activities to be performed during lessons, and (h) a list of answers to activities proposed. An example of these teacher's guidelines, for lesson 4, is given in Appendix 2. After the design process, we defined the Design Principles and the Objectives of the course, described in detail in Appendix 3.

\subsection{Content of lessons}

Our TLS on the concept of mass is called ' $E=m c^{2}$ and the Weight of Energy' and was aimed at secondary physics teachers with some experience. It was designed with 8 lessons, two hours long each, divided into three blocks, namely: classical mechanics (3 lessons), electromagnetism (2 lessons), and relativity (3 lessons). We began by discussing the concepts of mass, force, inertia, energy, and momentum in classical mechanics, so as to emphasize their relationships with Newton's laws. Next, two lessons were devoted to electromagnetism because, although this theory does not deal explicitly with mass, it did provide the extension of the concept of inertia to the case of massless fields and paved the way for special relativity, as indicated by the very title of Einstein's 1905 paper 'On the electrodynamics of moving bodies'. The concepts of energy, momentum and inertia, present in both classical mechanics and electromagnetism, were re-signified by the latter. Electromagnetic phenomena, such as radiation [22], motivated a revision of Newtonian concepts. With the development of relativity, they acquire both a new coherence and novel meanings. The last three lessons, on relativity, concentrate on the resignification of concepts, by discussing new formulations of old equations and presenting their worldview. This discussion relies tacitly on the notions of epistemological ruptures, proposed by Bachelard, and of incommensurability, stressed by Kuhn [23]. This strategy to discuss the re-signification of mass can be also inferred from the sequence of topics and didactic intentions presented in Table 1.

\section{Research context and questions}

Our DBR includes topic of modern physics, especially the notion of mass in relativity, which involves ontological controversies even among practicing physicists [24]. Therefore, we found it convenient to rely on ideas from the Didactic Transposition Theory, proposed by Chevallard [11], which discusses the transformation of scholarly knowledge into taught knowledge. This theory is wellknown among researchers in science education and, in our work, it is instrumental in specifying the different environments which knowledge is dealt with. According to Chevallard, there are three different spheres in which knowledge intervenes, along a chain that begins with its production and ends at school, which he calls scholarly 
Table 1: Content of the 8-lessons

\begin{tabular}{|c|c|c|}
\hline title & content & didactic intention \\
\hline $\begin{array}{l}\text { Lesson 0: } \\
\text { Classical Universe }\end{array}$ & $\begin{array}{l}\text { General Contents of the Universe - Space and } \\
\text { Time - Mass and Gravitational field - Newton's } \\
\text { Gravitation Law - Newton's Dynamics Laws - } \\
\text { The Universe as a stage, with material actors }\end{array}$ & $\begin{array}{l}\text { - reinforce and give meaning to known concepts } \\
\text { to be deconstructed later } \\
\text { - address on the role of mass, energy, force and } \\
\text { Newton's laws in classical mechanics }\end{array}$ \\
\hline $\begin{array}{l}\text { Lesson 1: } \\
\text { Energy and Work in } \\
\text { Classical Physics }\end{array}$ & $\begin{array}{l}\text { Energy and Momentum related with space and } \\
\text { time - The Role of Force - Gravitational Potential } \\
\text { Energy - Mass and Inertia }\end{array}$ & \\
\hline $\begin{array}{l}\text { Lesson 2: } \\
\text { Bound Systems and } \\
\text { the Hydrogen Atom }\end{array}$ & $\begin{array}{l}\text { Confined Systems - Potential Well - Coulomb } \\
\text { Potential - Energies of Atom - Binding Energy } \\
\text { - Epistemological discussion - Exothermic Reac- } \\
\text { tions }\end{array}$ & $\begin{array}{l}\text { - discuss the bound systems and exothermic re- } \\
\text { actions to relate with relativistic view later }\end{array}$ \\
\hline $\begin{array}{l}\text { Lesson 3: } \\
\text { Energy and Momen- } \\
\text { tum in Electromag- } \\
\text { netism }\end{array}$ & $\begin{array}{l}\text { Charges and Fields - Energy of fields - Energy } \\
\text { Stored in a Capacitor - Energy of a point-charge } \\
\text { - Electromagnetic Waves - Momentum of wave } \\
\text { and its Re-signification }\end{array}$ & $\begin{array}{l}\text { - show that electromagnetism brings massless } \\
\text { fields into the game } \\
\text { and fields carry both energy and momentum }\end{array}$ \\
\hline $\begin{array}{l}\text { Lesson 4: } \\
\text { Radiation and } \\
\text { Action-Reaction }\end{array}$ & $\begin{array}{l}\text { Electric Field Lines - Deceleration of Electric } \\
\text { Charge - Origin of Radiation - The Breaking of } \\
\text { the Third Newton's Law - Momentum Conserva- } \\
\text { tion - Re-signification: Wave carries Momentum }\end{array}$ & $\begin{array}{l}\text { - break the Newton's } 3^{\text {rd }} \text { law and emphasize the } \\
\text { rupture of mechanics } \\
\text { - introduce a new question: How can a massless } \\
\text { object carry momentum? Momentum begins to } \\
\text { be disconnected from mass }\end{array}$ \\
\hline $\begin{array}{l}\text { Lesson 5: } \\
\text { Relativity: relative } \\
\text { and absolute enti- } \\
\text { ties }\end{array}$ & $\begin{array}{l}\text { Relativity in Spatial Rotations - Special Relativ- } \\
\text { ity Theory - Lorentz Transformations - Scalar } \\
\text { Products - Relativistic Interval - Proper Time }\end{array}$ & $\begin{array}{l}\text { - construct the meaning of dot product in } 3 \text { - } \\
\text { dimensional space for relating with doc product } \\
\text { of } 4 \text {-vectors later } \\
\text { - give meaning to the existence of relativistic } \\
\text { invariants }\end{array}$ \\
\hline $\begin{array}{l}\text { Lesson 6: Relativity: } \\
\text { Mass and Energy }\end{array}$ & $\begin{array}{l}\text { The Classical Coil-Magnet Problem - Four- } \\
\text { Momentum - Energy as the fourth Component } \\
\text { of 4-vector - Energy and Inertia - Invariant Mass } \\
\text { - Re-signification of Mass }\end{array}$ & $\begin{array}{l}\text { - perform the dot product (p.p) and introduce } \\
\text { the mass as an invariant } \\
\text { - discuss } \mathrm{m}=\gamma \mathrm{m}_{0} \text { - implications for teaching } \\
\text { inertial mass } \mathrm{X} \text { rest mass } \\
\text { - mass X energy: discuss the mathematical and } \\
\text { ontological meaning }\end{array}$ \\
\hline $\begin{array}{l}\text { Lesson 7: } \\
E \quad=m c^{2} \quad \text { in } \quad \text { ac- } \\
\text { tion... }\end{array}$ & $\begin{array}{l}\text { Exothermic Reactions - Photon Energy - Relativ- } \\
\text { ity and Lavoisier - Weight of Hydrogen - Weight } \\
\text { of Deuteron - Proton Weight - Re-signification: } \\
\text { Energy Weighs! }\end{array}$ & $\begin{array}{l}\text { - show that energy weights in bound systems: } \\
\text { combustion / atom / nuclei / proton } \\
\text { - show the weight of energy in the case of proton } \\
\text { - } 99 \% \text { of its mass is energy } \\
\text { - deconstruct mass in Newtonian sense: trans- } \\
\text { fer the property of inertia and attractiveness to } \\
\text { energy }\end{array}$ \\
\hline
\end{tabular}

knowledge, knowledge to be taught, and taught knowledge, as represented in Fig.2. The transition from a given sphere to the next one is called a transposition. The first of them is called external transposition, since it happens outside school and is represented by arrow (1). It is then followed by the internal transposition, arrow (2), which consists in the transformation and adaptation of knowledge from textbooks. This transposition is performed by teachers and occurs inside the classroom.

In the vast majority of cases, the action of high school teachers occurs between the second and third spheres. Chevallard stresses that the preparation of a lesson 'is certainly to work with the didactic transposition (or, even better, to work in the didactic transposition)' [11, p.20, our translation]. This makes it clear that this teacher does not perform the whole transposition but, rather, works on it, since it has already begun previously.

In this work, we are mainly concerned with two aspects of the teaching process, as described by Chevallard, namely the didactic intention (DI) and the epistemological surveillance (ES). According to him, the transposition of knowledge between different spheres should be car- ried out with a didactic intention, without which the teaching goals become blurred. In the transformation of knowledge into contents to be taught, the didactic intention determines the approaches to be employed and, thus, the same knowledge can be transposed under different perspectives. For example, a specific subject, such as the electric field, can be approached with different emphases regarding historical, conceptual, mathematical, experimental, or epistemological aspects, depending on the didactic intention. Thus, even if the concept of electric field occurs in the three spheres of knowledge, the way it is treated in each of them depends on a didactic intention. Chevallard himself expresses the difficulty in defining the didactic intention and states, in short, that it is an intention to teach $[11$, p.5]. This intention works as guides, which conduct the transposition of knowledge from the scholarly environment up to the classroom.

Besides the DI, there is another important concept, which Chevallard calls epistemological surveillance (ES), a tool which allows the teacher to move away from the misleading familiarity of its subject and to question ordinary ideas and simple evidences. The practice of the 


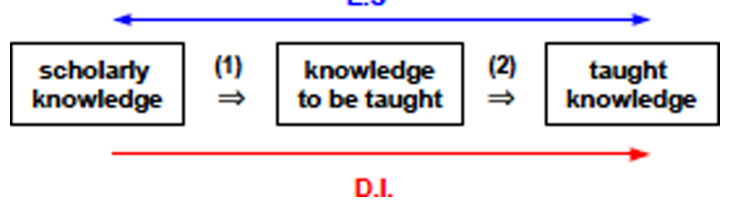

Figure 2: Spheres of knowledge in Didactic Transposition

ES requires the constant scrutiny of the didactic intention and the assessment of whether or not what is being taught agrees with established objectives. These two concepts of the didactic transposition are schematically represented by the arrows DI and ES, in Fig.2 The DI arrow is parallel to the direction of knowledge flow, since it guides the transposition process, whereas the ES is a double arrow, so as to represent an attitude by the teacher of going back and forth to ensure the goals of teaching. In the present research, a didactic intention was present from the very beginning, for the supporting material was written before both the organization of the design group and of the development of the TLS. Along the design process, this DI was brought closer to the classroom, as suggested in Fig.3, which now includes our written material and represents the classroom by taught knowledge.

An important feature of the TLS process is the creation of a scenery for the development of the research, in which the research questions could be properly formulated. In our case, the TLS is inserted into the context of curricular innovation and is aimed at promoting a classroom environment suited for lessons on modern physics contents by an implementer teacher. At present, there are many researchers dealing with didactic sequences, employed mostly to investigate the process of student learning, and derived from activities applied to the classroom [25-31]. In this aspect, our study is different, because the aim the TLS designed was to investigate the performance of the implementer teacher. In curricular innovation, teacher training is very relevant since, at once, the appropriation of modern physics contents is essential and cannot be taken for granted. We employed DBR/TLS methodology to investigate questions related to practices involving innovative contents. The specific didactic intention, represented in Fig.3, guided the writing of the supporting material and, afterwards, was also present in the design process and embodied in the instructional material produced for its implementation.

Our research questions were focused on the practice of the implementer teacher and, therefore, occur in the implementation step of the TLS. They concern both the appropriation of the DI and of its goals by this teacher. With this purpose in mind, we investigated possible discontinuities in the DI flow and, if so, the reasons that motivated them. In this sense, our investigation is located in the taught knowledge sphere of didactic transposition, as indicated in Fig.4.

In general terms, design processes yield didactic sequences which, in principle, could be transferred to other contexts and used by other teachers. Therefore, the transferability of didactic materials is an essential part of the procedure and it is important to understand whether or not underlying didactic intentions can be apprehended by implementer teachers. Owing to general features of physics knowledge and its structural nature, which are discussed in section 7 , the teaching of an innovative content, such as special relativity, requires skills from the teacher which are different from those needed to teach classical subjects, and this may affect the transferability of didactic materials. This is our point of departure and we concentrated on two main questions, namely:

(i) Is the design process enough to prepare a teacher to deal with innovative contents?

Didactic Transposition

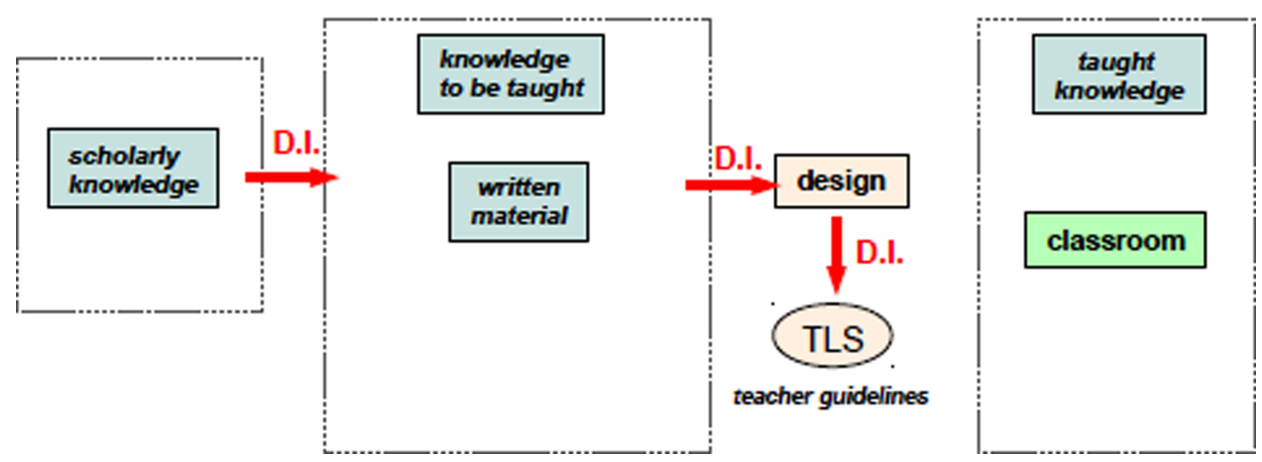

Figure 3: Design process within didactic transposition 
Didactic Transposition

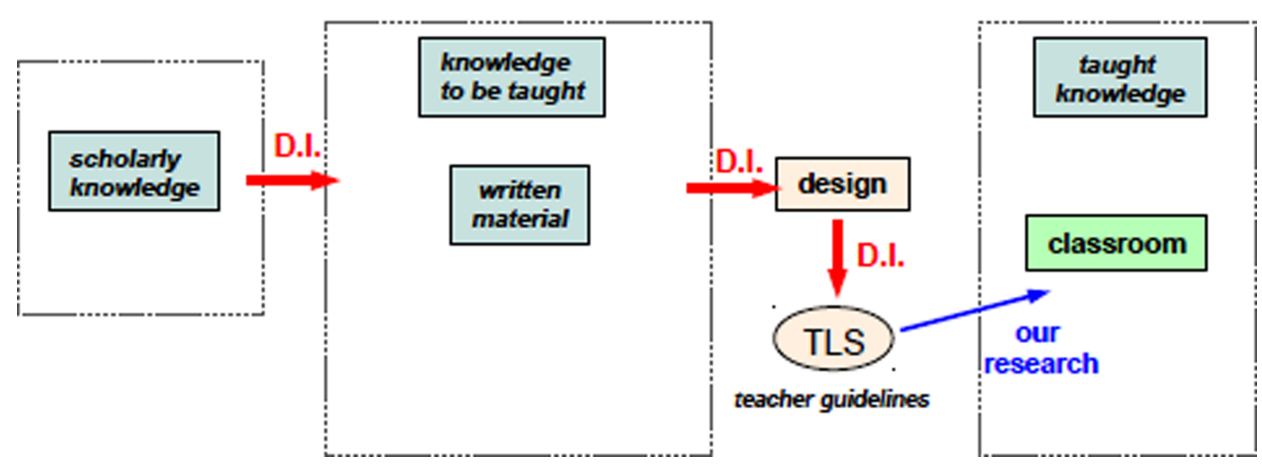

Figure 4: Our research

(ii) What is the influence of a teacher's previous experience on the appropriation of a didactic intention?

In the context of curricular innovation, attention must be paid to teacher training, as emphasized by Davis [32] and Pintó [33]. If a didactic material brings a higher level of innovative content, it is expected that difficulties teachers have in using it should increase and, correspondingly, the degree of transferability of this material is reduced. In general, innovative proposals aim at influencing directly the classroom environment, and the teacher is a rather sensible actor. This motivates our first question, which regards the skills a teacher must have to deal properly with modern physics subjects. The second question derives from results produced by several researchers, who emphasize that teachers use in the classroom a kind of knowledge acquired along their practice [34-37]. Shulman defines pedagogical content knowledge (PCK) as knowledge 'which goes beyond the subject matter per se to the dimension of subject matter knowledge for teaching' [38, p.9]. Although PCK plays an important role in teaching, the previous experience we refer to in our study is related mostly to specific physics contents and is not, in fact, a general pedagogical content knowledge. Our research aims to identify a pedagogical knowledge strictly related to specific content, required to teach modern physics topics. As the didactic sequence presented in this work covers changes in the concept of mass in three different frameworks, namely classical mechanics, electromagnetism, and relativity, we could observe the performance of the implementer teacher in all those subjects. This gave us the unique chance of assessing the performance of a single person in lessons with either traditional or modern contents. It's important to mention that as our research was focused on the implementer teacher, the didactic sequence designed has the main feature of a teaching sequence and not a TLS, since it does not involve learning issues. On the other hand, we followed the TLS methodology to design, implement and collect data, so that the term TLS was employed throughout the research.

\section{Data collection and analysis}

The methodology associated with the TLS can generate a huge amount of data for research which, in general, must be delimited and reduced in function of the research questions posed. According to Triviños [39], in qualitative research, the data are collected by three different means, namely observation, interviews, and document analysis. Our research focused on the teacher's actions and the eight lessons delivered were entirely video recorded. In addition, at every two lessons, a personal report was requested to the implementer teacher, in which he was allowed to make his own comments and state the difficulties found, together with impressions, and sensations concerning both himself and students. Four personal reports were collected and became essential to the documental analysis. The recording of lessons focused on the performance of the teacher, on his notes on the blackboard, and on interventions by the high school physics teachers. The average attendance was 16 people per Saturday.

As the TLS content involved three different blocks, regarding classical mechanics (lessons 0,1 , and 2), electromagnetism (lessons 3 and 4), and relativity (lessons 5,6 , and 7 ) and considering the qualitative nature of our research, we chose one lesson in each block to be analyzed, so as to represent the three theories involved. This allowed us to contrast his performance in both traditional and innovative contents. The lessons analyzed were:

- Lesson 1 - Energy and Work in Classical Physics

- Lesson 4 - Radiation and Action-Reaction

- Lesson 6 - Relativity: Mass and Energy

\subsection{Method of analysis}

Before starting the analysis, we defined the didactic intention (DI) of the TLS and specified the important features of each lesson. This course can be considered as a kind of didactic narrative, aimed at conveying a message. So, all topics dealt with were carefully ordered beforehand, so as to yield a global meaning, centered on the re-signification of mass. In this ordering process, we found it useful to 
classify them as either mean-like or end-like. Mean-like elements are contents which are part of the main axis of the course, but act in supporting the main narrative. They are components of the basic conceptual network and their explicit introduction is intended to bridge possible gaps of content, strengthen important topics, and pave the way for more advanced themes. For instance, in lesson 3, one discusses the energy stored in a capacitor, in order to illustrate that energy can be stored in the electric field so that, afterwards, it can be associated with the momentum and inertia of electromagnetic waves. The role of mean-like elements is, therefore, mostly local.

End-like elements, on the other hand, concern contents considered as essential to discussing the re-signification of mass. They constitute the main track of the didactic narrative and act globally towards both structuring physics knowledge and stressing the meanings of concepts by means of ontological and epistemological discussions. In this way, it regards two complementary dimensions of scientific knowledge, which may be called extension and depth [40]. Mean-like and end-like elements play a different role within the didactic sequence, as emphasized in Table 2, and in every lesson, both kinds were present. A pictorial image representing these elements is shown in Fig.5, where the end-like elements are represented by arrows which contribute to the global aim of the sequence and, the mean-like elements are cross arrows, playing the role of supplying local gaps of content.

\subsection{The Data}

Our analysis focused on 'how' the implementer teacher developed each lesson and whether he conveyed properly the didactic intention that guided the design process. As a narrative, the TLS is close to a theater play, where many different languages work together, such as music, gestures, speeches, clothes, lighting, and so on, and yield a global effect, which conveys the intended message. In the TLS, we identified five distinct elements, called DI components, which work together to convey the didactic intention.

Table 2: Role of mean-like and end-like elements

\begin{tabular}{ccl}
\hline elements & effect & role \\
\hline mean-like & local & $\begin{array}{l}\text { supply gaps and strengthen already } \\
\text { known contents } \\
\text { structure knowledge and introduce new } \\
\text { end-like }\end{array}$ globanings
\end{tabular}

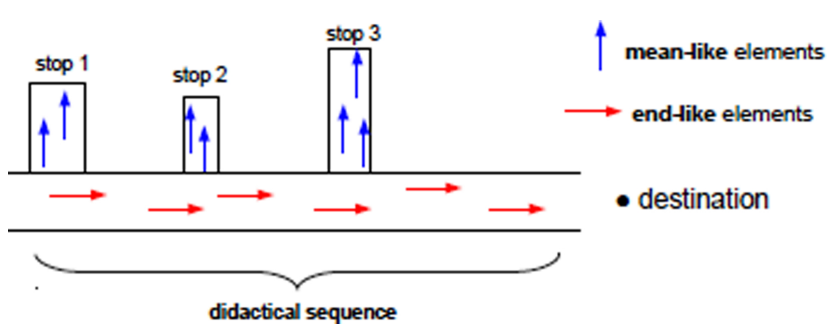

Figure 5: Mean-like and end-like elements [17]
They cooperate to create the didactic narrative and turn the analysis of the data provided by the implementer teacher both better defined and objective.

The identification of these DI components departed from a work by Karam, who assessed the didactical performance of an experienced physics lecturer. According to him,

the categorization system can also be used to analyze physics lessons in high school, textbooks, and other teaching materials. Moreover, the analytical tool can be implemented in teacher training programs to discuss the implications of different didactic approaches. An envisaged future goal of this research is to establish objective criteria to characterize the notion of didactic quality of explanations [41, p.17].

From the eight categories he created, we took three, merged into two, and developed other three. Our five DI components, called are Ordering, Mathematics, Signification, Epistemology, and Re-signification, are shown in Table 3, together with their abbreviations.

Below, we describe our DI components:

1. Ordering: to preserve the entirety of the didactical narrative, by keeping the established sequence of ideas. This component is quite important, since the ordering of ideas in the TLS is intentional and aimed at structuring the course. The presentation of topics should follow the order proposed during the design phase, so as to allow the changes in the concept of mass to become meaningful.

2. Mathematics: to represent concepts and their relationships by means of mathematical structures, which could support physical interpretations later on. This DI component encompasses the introduction of both equations and short deductions. For instance, in lesson 1, the kinetic energy and impulse theorems are deduced from Newton's second law, so that they can be later applied to collision problems, in order to stress relationships between inertia, force, momentum, and mass. This component is predicted to occur many times during the TLS, in the interplay between mathematical formalism and physical interpretation. It emphasizes the cohesion of theoretical structures and show that descriptions of some phenomena are justified by laws which are expressed mathematically.

3. Signification: to establish the meaning of key concepts. This TLS deals with a dimension of knowledge

Table 3: DI components

\begin{tabular}{lll}
\hline abbreviation & DI components & Karam's categories \\
\hline ORD & Ordering & \\
MAT & Mathematics & $\begin{array}{l}\text { Mathematics and Inter- } \\
\text { preting }\end{array}$ \\
SIG & Signification & \\
EPI & Epistemology & Epistemology \\
RE-SIG & Re-signification & \\
\hline
\end{tabular}


which may be called extension [40], since it comprehends classical mechanics, electromagnetism, and relativity. Although the TLS is centered around the concept of mass, we found it necessary to discuss the meaning of other instrumental concepts during the design process, such as binding energy, potential well, field, momentum, and energy. This is motivated by the understanding that physics knowledge is organized into structures, endowed with both coherence and conceptual hierarchies [42], which allows it to be represented by networks. Therefore, the signification of physical concepts is produced by their relationships with surrounding concepts.

4. Epistemology: to discuss aspects of the nature of physical knowledge. This component is related to aspects of 'doing physics' and to how knowledge is organized and is present in all lessons of our TLS. In lesson 2, for example, we discuss the Hydrogen atom and rely on epistemological elements, such as the roles of phenomenology, models, and theories in physics.

5. Re-signification: to discuss changes in the meaning of concepts. This DI component is central to our didactic sequence, since our aim is to re-signify the concept of mass, together with the notions inertia, energy, action-reaction, and momentum. Even if these concepts are known by high school physics teachers, changes in meaning from a context to another are not. The main aim of the TLS is to bridge this gap.

After identifying these five components, we broke the three lessons analyzed into a list of tasks that the implementer teacher had to accomplish, according to the instruction manual. These tasks were then classified as either mean-like or end-like, and one checked the occurrence of gaps in the flow of each of the five DI components, along the performance of the implementer teacher. Results depended on the lessons and theories involved, since the presence of different DI components in each of them is not uniform. However, if for example, signification was planned in a given task, the analysis focused on its occurrence at that moment. Thus, our analysis consisted in assessing: (i) whether the implementer teacher followed the plans for the five DI components and (ii) how he did it. The list of tasks and their classification, for the three lessons analyzed, is presented in the tables of Appendix 4.

In all lessons, an ordering of tasks was planned and, in all cases, after an end-like content, a little break for reflection was scheduled. These protected intervals, aimed at epistemological discussions, are called Structuring Moments (SM) and devoted to the reorganization of physical knowledge, using the ideas discussed previously. Their aim is to promote the re-structuring of concepts and to stress changes in their meanings. The corresponding structures of the lessons analyzed with the Structuring Moments are shown together in Appendix 4.

\section{Results}

The five didactic intention components presented in the previous section were used to analyze the lessons 1, 4 and 6 delivered by the implementer teacher. In a schematic form, the results are displayed in Figs.6, 7, and 8 and the identification of the DI components is presented in the last column. On the left vertical axis, we show the time prescribed for each task in the teacher's guidelines, and on the right, the time that the implementer teacher took to perform them. Besides the list of tasks and their classifications, the figures also show, in the last column, the occurrence of gaps in the DI components in each task.

\begin{tabular}{|c|c|c|c|c|}
\hline & Lesson 1 - Energy and Work in Classical Physics & Duration: $2 \mathrm{~h} 01 \mathrm{r}$ & $=121 \mathrm{mi}$ & \\
\hline$n^{0}$ & list of tasks & classification & \multirow{3}{*}{$27 \min$} & DI components \\
\hline 1 & $\begin{array}{l}\text { To place the energy in the stage and } \\
\text { justify with Nöether's theorem }\end{array}$ & mean-like & & ORD \\
\hline 2 & $\begin{array}{l}\text { To present the role of force: Newton } X \\
\text { Leibniz, impulse and kinetic energy theorems }\end{array}$ & mean-like & & $\begin{array}{l}\text { ORD } \\
\text { SIG }\end{array}$ \\
\hline 3 & $\begin{array}{l}\text { To deduce the conservation of energy from } \\
\text { kinetic energy theorem for the Earth-Sun system. } \\
\text { Activity } 1 \mathrm{~A} \text {. }\end{array}$ & mean-like & $43 \mathrm{~min}$ & ORD \\
\hline 4 & $\begin{array}{l}\text { To discuss the relationship between inertia and force in a } \\
\text { collision problem. Activity } 1 \mathrm{~B} \text {. }\end{array}$ & end-like & \multirow{4}{*}{$\begin{array}{l}95 \mathrm{~min} \\
116 \mathrm{~min}\end{array}$} & SIG \\
\hline & Meaning: inertia & M. S. & & \\
\hline \multirow[t]{2}{*}{5} & $\begin{array}{l}\text { To discuss the properties of matter: inertia and attractiveness } \\
\text { Newtonian universe }\end{array}$ & end-like & & SIG \\
\hline & Meaning: gravitational and inertial mass & M. S. & & \\
\hline
\end{tabular}

Figure 6: DI components - lesson 1 


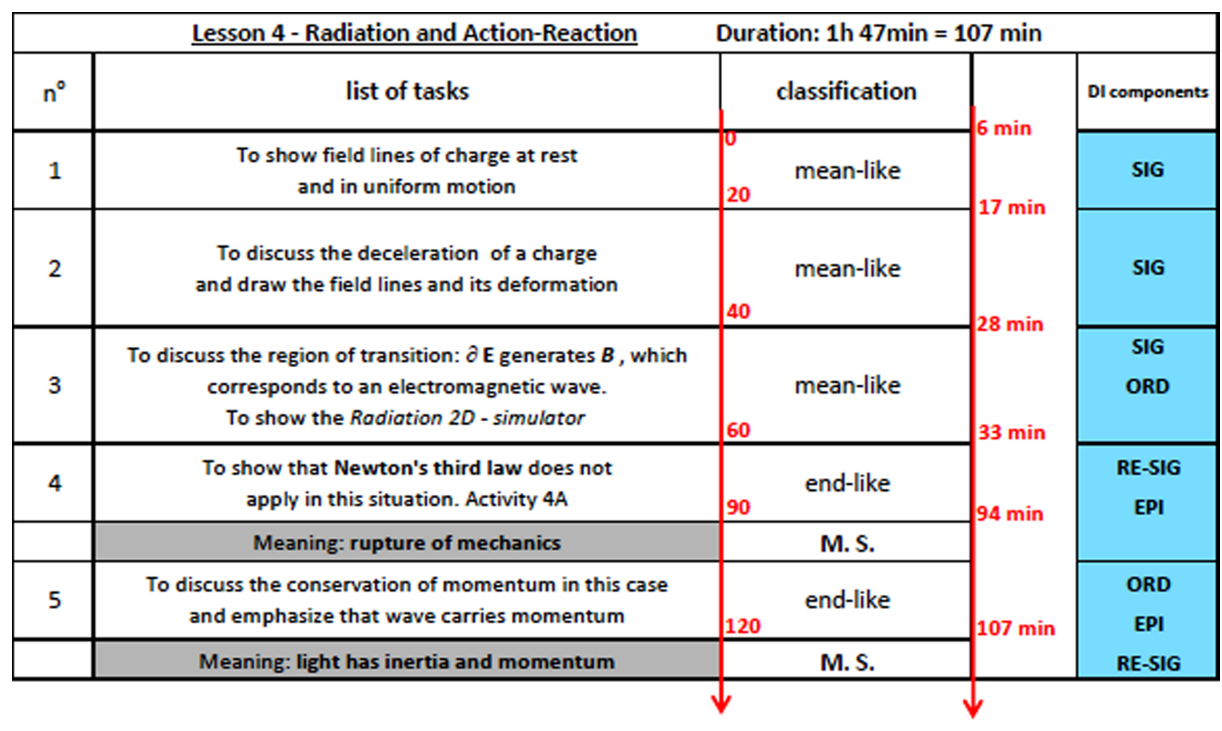

time suggested by manual

time of implementer teacher

Figure 7: DI components - lesson 4

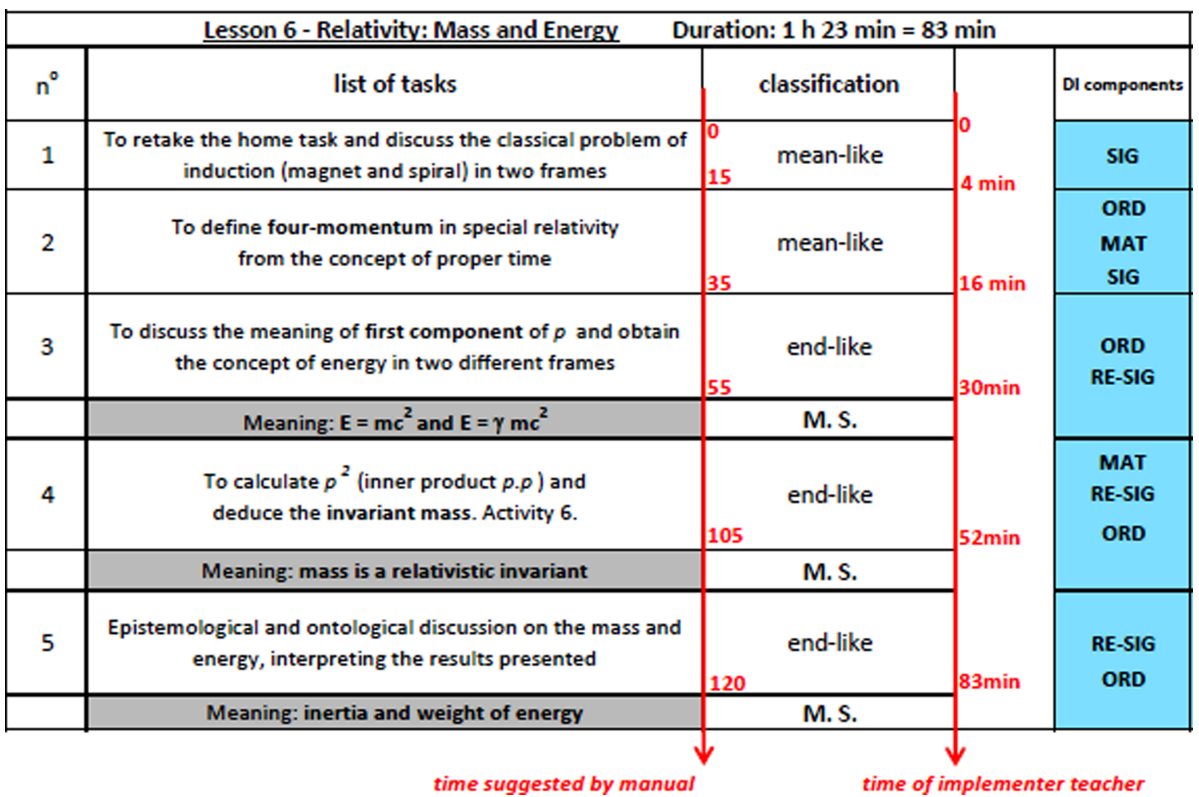

Figure 8: DI components - lesson 6

The occurrence of breaks of two components was observed, in the lesson 1, namely Ordering and Signification, as indicated in the last column. The former occurred in tasks 1, 2, and 3 and the latter in tasks 2, 4, and 5 .

The implementer teacher completed all tasks of electromagnetism, and the occurrence of breaks of the components Signification were observed in tasks 1, 2 and, 3; Ordering, in tasks 3 and 5; Re-signification, in tasks 4 and 5; and Epistemology in tasks 4 and 5.

Finally, in the lesson 6 , the components Signification was broken in tasks 1 and 2; Ordering, in tasks 1, 2, 3, and 4; Mathematics, in tasks 2 and 4; and Re-signification, in tasks 3,4 , and 5 .

\section{Discussion of results}

The analysis of the implementer teacher's performance in our three representative lessons is summarized in Fig.9, where the end-like tasks are shown in red. As described in Section 4, the occurrence of breaks in a DI component indicates a deviation from the activities planned. Results suggest a connection between the occurrence rates and the physical contents involved in each block.

With respect to the DI component Mathematics, there were no occurrences in lessons 1 and 4, which is an interesting fact. Regardless of the content involved, the relationship between physics and mathematics, which structures the former, is an involved one, as widely ac- 


\begin{tabular}{|c|c|c|c|c|c|c|}
\cline { 2 - 7 } \multicolumn{1}{c|}{} & \multicolumn{2}{c|}{ Lesson 1 - Mechanics } & \multicolumn{2}{c|}{ Lesson 4 - Electromagnetism } & \multicolumn{2}{c|}{ Lesson 6-Relativity } \\
\hline $\begin{array}{c}\text { D.I. } \\
\text { components }\end{array}$ & Tasks & $\begin{array}{c}\text { Rate of } \\
\text { Occurrence }\end{array}$ & Tasks & $\begin{array}{c}\text { Rate of } \\
\text { Occurrence }\end{array}$ & Tasks & $\begin{array}{c}\text { Rate of } \\
\text { Occurrence }\end{array}$ \\
\hline$O R D$ & $\mathrm{~T} 1, \mathrm{~T} 2, \mathrm{~T} 3$ & 3 & $\mathrm{~T} 3, \mathrm{~T} 5$ & 2 & $\mathrm{~T} 2, \mathrm{~T} 3, \mathrm{~T} 4, \mathrm{~T} 5$ & 4 \\
\hline$M A T$ & - & - & - & - & $\mathrm{T} 2, \mathrm{~T} 4$ & 2 \\
\hline$S I G$ & $\mathrm{~T} 2, \mathrm{~T} 4, \mathrm{~T} 5$ & 3 & $\mathrm{~T} 1, \mathrm{~T} 2, \mathrm{~T} 3$ & 3 & $\mathrm{~T} 1, \mathrm{~T} 2$ & 2 \\
\hline$E P I$ & - & - & $\mathrm{T} 4, \mathrm{~T} 5$ & 2 & - & - \\
\hline$R E-S I G$ & - & - & $\mathrm{T} 4, \mathrm{~T} 5$ & 2 & $\mathrm{~T} 3, \mathrm{~T} 4, \mathrm{~T} 5$ & 3 \\
\hline
\end{tabular}

Figure 9: Results from analysis

knowledged by both scientists and teachers. Therefore, mathematical aspects tend always to be carefully presented, in both high school and undergraduate classes. During a physics lesson, a teacher usually makes use of some mathematical skills, which may range from a simple proportionality relation to more complex equations or logical reasoning. In this sense, mathematics constitutes a hard core of physics, which must be respected. Different teachers may approach a given topic presenting motivations, ideas, examples, in many different ways. Nevertheless, the dispersion in the dealing with mathematical structures tends to be smaller. Any lesson on the Coulomb law must pass through the same equations. It is as if the use of the same key equations was a compulsory task for physics teachers and, in general, this is an important part of their training. This requires a domain of instrumental rules, with no reference to particular physics contents [43].

Our results show that the implementer teacher was indeed able to deal with the relevant equations in the lessons of mechanics and electromagnetism. However, in the lesson on relativity, two derivations were expected, which were mathematically simple and conceptually involved, concerning the relativistic energy and the inner product of four-momenta. In those cases, he did not perform the operations step by step, but just jumped directly to equations already written in the slide he was projecting.

The DI component Ordering, was observed in the three lessons considered. In lesson 1 , it occurred associated with the insertion of unexpected contents, which induced a dispersion of the didactic intention in that task. In other instances, the teacher reversed the orders of some topics, as, for example, in lesson 4, when he presented the Radiation-simulator of electromagnetic waves before signifying the basic theoretical radiation mechanism. In the relativity lesson, this component occurred at a higher rate, as indicated in Fig. 9, and was especially frequent in end-like tasks.

The occurrence of break in Ordering cannot be attributed to a lack of preparation by the implementer teacher, since we could verify that he prepared himself very carefully and used his own notes during the lessons. This leads us to assume that this component occurred owing to unforeseen circumstances during the lectures.
These unexpected situations are part of the daily life of teachers and, indeed they happen often inside a liberal classroom. In this course, students were asked to interrupt the teacher in order to pose questions. As this TLS involves innovative topics, these situations occurred frequently. In some occasions the teacher, after being interrupted by a question, even if on the topic being discussed, seemed to loose his track and to deviate from the initial plan. We noticed that the occurrence of Ordering and the corresponding inversion of tasks were always associated with the raising of questions by participants. Moreover, the rate of occurrence of this component in lesson 6 was higher, indicating a relationship with the innovative character of its content - relativistic dynamics - and the designed sequence was more difficult to be maintained.

As far as the component Signification is concerned, occurrences were observed in the three lessons analyzed. They appeared three times in mechanics, three in electromagnetism, and two in relativity. This result is similar to Ordering, which suggests that these two components are correlated. In the lesson on mechanics, the teacher failed to discuss activity $1 \mathrm{~B}$ (in task 4), regarding the collision between two masses. This activity was designed to give meaning to the relationship between force and inertia. Also, he skipped the closing discussion, intended to emphasize the properties of inertia and attractiveness of mass. As a consequence, the Signification of these concepts was hindered. In the lesson on electromagnetism, this component appeared associated with the form of the electric field produced by charges, both at rest and accelerated. A simulator of field lines was expected to be shown after the discussion of the origin of radiation, interpreted as deformations of field lines. However, this order was inverted, and the construction of the meaning designed for electric field lines was lost. In the case of relativity, Signification appeared at the very beginning, with the omission of a discussion proposed for the classical current induction problem in two different frames. There were also occurrences of Signification related to the introduction and interpretation of four-momentum.

The appearance of both Ordering and Signification in the three lessons discussed, involving rather different contents, suggests that they are not related to a specific subject. In most cases, these components appeared 
together and, we noticed that interruptions due to questions posed by participants took the teacher away from his track. This situation is usual when one teaches a subject for the first time. In the reports collected at the end of each lesson, the implementer teacher wrote:

"Regarding person X, I felt anxious in some moments, for this was the first time I made such discussions and this may have transpired somehow" (written report after lesson 1).

And also,

"What was hardest in this lesson, no doubt, was the apprehension and jitters of the first lesson. The fact that this course happens in the Institute of Physics of USP had a weight as well" (general written report about the whole TLS).

Sometimes, when the teacher was requested to answer questions about a specific concept, we noted that, in critical situations, his speech veered off, and he moved to a different point of the course axis. This suggests that, in order to perform the components Ordering and Signification, a broad acquaintance with mean-like and end-like dimensions of the TLS is needed, which are specific realizations of the dimensions depth and extension of physics knowledge [40].

The fourth DI component, Epistemology, is considered as a kind of desirable seasoning to the course. Its absence does not prevent technical discussions, but its presence does improve it, by fostering important discussions. Our results show that this component did not occur in lessons 1 and 6 . However, in the lesson on electromagnetism, the teacher became less secure when he discussed the breaking of Newton's third law. He also failed to relate epistemologically the electric field to momentum and inertia, as prescribed by the instructions in the manual, for the last task of lesson 4.

Finally, with respect to the Re-signification, we noted that in the mechanics lesson, this component was not planned, since the concepts approached are well-known. On the other hand, in electromagnetism and relativity, this becomes an explicit didactic intention, aimed at re-signifying the inertia of the electromagnetic field, the limited validity of Newton's third law and the very concept of mass. Our results show that breaks in this DI did occur in lessons 4 and 6 .

During lesson 4, the teacher deals with the important limitations of Newton's law as if they were natural, instead of considering it an evidence of an important theoretical rupture. Again, in lesson 6, motivated by questions by participants, the teacher mixes the concept of invariant mass (by changes of frame) and the conservation of mass in exothermic reactions. In this same lesson, the teacher refers twice to an example of electrons gaining energy in a particle accelerator, and says that, owing to the invariance of mass, the 'electron does not become heavier'. However, it was planned for the next lesson (the seventh), a discussion showing that the weight of a body is associated with its energy. These two instances, associated with (i) the relationship of invariant mass with the exothermic reaction and (ii) the weight of bodies, suggest that the teacher had difficulties in integrating the purposes of the two successive lessons, treating them as being disconnected.

In order to highlight these occurrences, we present three excerpts of the implementer teacher reports, which seem to suggest an interior unrest involving Newtonian and relativistic conceptions of the world, produced by himself after lesson 6 . They suggest a confused fusion of these two theories (Newtonian mechanics and relativity) to explain some phenomena, which could be associated with an epistemological insecurity.

Transcriptions of teacher's talk - lesson 6

[46:08 - 48:00] Because its mass [refers to an electron] will increase when it approximates... This construction one makes in our mind maybe needs to be reformulated. Because one lives in a classical world again, a world of fixed masses, firm masses, defined masses,... and maybe in the world of energy... maybe the energy suffers the relativistic variation and it manifests classically in a way that one translates in Newtonian mechanics... but this has limitations when one goes from a model to another one [shifts from a theory to another one]... in fact, this is a problem! I am trying to raise conjectures... I don't have answers for them.

[48:08 - 49:33] The issue is: this inertia, we are going to talk about in a while... Would this inertia be an attribute of mass or would this inertia be an attribute of energy, which manifests itself in the mass of classical world?

[52:48 - 53:10] When I write this [refers to expression $E=\gamma \mathrm{mc}^{2}$ ], one should not interpret that a body gains mass. One has to interpret that, in gaining energy, classically it manifests as mass. This is only a way of interpreting classically what is happening in relativity theory. It does not mean that the body became heavier.

\section{Concluding remarks}

The research presented in this work was based on the performance of a teacher in the implementation of a didactic sequence designed using the DBR methodology. The main research questions concerned the adequacy of the design process to prepare a teacher to deal with innovative content and the role played by his previous experience.

The lessons delivered were analyzed tracking a specific didactic intention (DI), which had five components and pervaded the TLS. They were considered as being broad enough for characterizing the nature of physics knowledge and called Mathematics, Ordering, Signification, Epistemology, and Re-signification. 
Results show that the difficulties in conveying the DI components were related to the innovative content of the subject discussed. As the teaching sequence progressed and modern physics contents became more frequent, the difficulties the teacher had in expressing the didactic intention increased. We noticed that difficulties were associated with the absence of a broader experience in teaching some specific contents. In particular, the flux of the Re-signification component was broken more often by the end of course, when innovative contents became more central.

This perception was derived from the observation of a single teacher, but it points to wider questions concerning both the teaching of physics and curricular innovation, which involves both changes in already existent structures and the re-contextualization of known contents. When facing an innovative situation, a teacher may feel the dilemma between either accepting new proposals or following his own conceptions, allowing for a gap between plan and practice. This kind of gap is neither rational nor intentional but, rather, it happens unwittingly in the teacher's action [45].

Our results indicate that the appropriation of the resignification of physical concepts is rather difficult. Traditionally, teacher training relies on textbooks, where scientific knowledge is normally organized and divided into didactical sectors, due mainly to pedagogical requirements. So, formal education tends to blur contrasts between theories, which remain, at best, tacit. In particular, during formal instruction, teachers are not trained to discuss several theories at once. When one has to deal with two competing theories, Kuhn's notion of incommensurability becomes relevant in education. For instance, classical mechanics and relativity assign the same symbols to key concepts such as space, time and mass, but with different meanings. Thus, the transit between theories requires a skill not demanded when just a single theory is taught. This may explain the difficulty the implementer teacher had.

In the teaching of relativity, for example, textbooks normally treat a re-signified mass, but tend to skip discussions that could shed light into its novel role in relativity, as compared to Newtonian mechanics. This kind of attitude suggests that epistemology is not needed for the understanding of physics. In our teaching sequence, the re-signification of mass was framed by epistemology and the change of its meaning was represented as a shift in its position in conceptual maps [24]. The course had the explicit didactic intention of promoting the understanding of why the meaning of mass has changed, how it has changed and the implications of that change.

Re-signification relies on the existence of stable structures. In the case of mass, a signification is produced by its insertion on closed structures, which are kept stable by the cooperation with other concepts supported by mathematical bonds. The meaning of mass is not within itself and, the very possibility of a re-signification depends on the perception that mass could participate into two different structures. Loose knowledge involves what Bachelard calls 'fabric of positive error', which may involve rational elements but, being partially woven, contains loose threads driven by subjectivity. Concepts are free to err and wander within loose structures and, therefore, cannot be re-signified [44].

In physics, the transition from classical mechanics to relativity involves a re-signification, a reframing of a conceptual network. Resignifying is an act of modification, necessarily preceded by a deconstruction of a conceptual network and of the relationships it contains. Resignifying involves unmaking old relations and replacing them with new ones.

Since internal coherence tends to make structures stable, the disarticulation of an existing structure, normally built with a lot of effort, involves an intellectual tension. Although the completion of a re-ordering of elements is accompanied by pleasure, in transition situations, the established knowledge resists changes. Usually, this kind of situation is accompanied by discomfort, as indicated by the implementer teacher himself. He had extensive experience and competence in what we are calling signification, provided by both his previous experience and the training in design process. However, this course was his first intensive experience in teaching the resignification of a concept. Perhaps this explains his difficulties, as stated in his own report, where he declares in a reflexive tone:

\begin{abstract}
"This was, in my view, the most complicated week in conceptual terms. It is the first time I give a lesson on theory of relativity. [...] I have detected a problem which certainly affects our pedagogical practice: I will call such problem as intellectual looseness 1 . When we are in possession of a conceptual part only, rarely we go beyond it. Little or no relations beyond our own concepts are established. Implications are very rare. It is this looseness which allows you to establish relations and implications. It is it that allows a teacher to analyze a question from students, submit it to the theory, create relations and see implications, not only theoretical, but also epistemological, methodological or even ontological ones. In this class, my intellectual looseness was very small and, therefore, I felt some discomfort to talk about the subject". (teacher's written report, after lesson 4 and 5).
\end{abstract}

In order to be able to go back and forth from classical mechanics to relativity, teachers must be acquainted with epistemology. An epistemological action requires experience in teaching, experience in perceiving the extension of knowledge, experience in traveling through the relationships which assign meanings to concepts and, also,

\footnotetext{
1 The term "intellectual looseness" is a translation of "folga intelectual" from Portuguese.
} 
experience in taking ontological plunges into concepts, exploring their content in depth. This kind of experience builds up a kind of ballast, which allows a teacher to navigate through the stormy seas of his classes full of questions. Even when the knowledge to be taught is limited, it is necessary for the teacher to know much more than he teaches. The intellectual looseness, associated with a ballast, supports the teacher's action inside the classroom. In unforeseen situations, as during students' questioning, the ballast ensures the stability of the lesson. The ballast gives weight to the teacher's word and enables him to be confident.

Our research has shown the existence of a novel kind of obstacle, of internalist nature, to the insertion of modern physics. This is in contrast with results from researches which disclose obstacles, such as the need for training teachers, the lack of instructional materials, lack of methodological consensus, and complexity of mathematical formalism, since the nature of these difficulties is either didactic or strategic [46]. In our case, the difficulties the teacher had were not didactical, pedagogical, methodological, or strategical but, rather, epistemological.

The experience of implementer teacher reported in this work can show that when dealing with innovative contents, attention must be paid to the development of epistemological skills by teachers, so that they can transpose this kind of knowledge to the classroom. The didactic transposition of modern physics contents and their insertion into curricula is a complex matter. Nowadays there are several textbooks on modern themes, but the training of high school teachers is usually not broad enough to allow them to deal with the implications that innovative topics bring. In general, teachers are left by their own and it becomes their individual responsibility to seek instruction from available sources.

The transferability of instructional materials and didactic sequences cannot be taken for granted without considering the formation of teachers. The more innovative the curriculum, the more difficult its transferability is expected to be. The transformation of signification into resignification has first of all to be appropriated by teachers. Only after this, one may expect them to have enough autonomy for creating and managing their own transpositions. The required task is: an active epistemological surveillance on the formation of teachers.

\section{Acknowledgements}

The author are very grateful to the implementer teacher of this study for his willingness to participate in this research, M. R. Robilotta for useful discussions and careful revision of the paper and the financial support by Coordenação de Apoio à Pesquisa (CAPES - Brazilian agency) (BEX 0816/15-9).

\section{Supplementary Material}

The following online material is available for this article: Appendix 1

Appendix 2

Appendix 3

Appendix 4

\section{References}

[1] E.A. Terrazzan, Perspectivas para a inserção da física moderna na Escola Média. Tese de Doutorado, Universidade de São Paulo, São Paulo (1994).

[2] F. Ostermann and M.A. Moreira, Caderno Catarinense de Ensino de Física 18, 135 (2001).

[3] M.A. Moreira and E.C. Valadares, Caderno Catarinense de Ensino de Física 15, 121 (1998).

[4] D.P. Gil, F. Senent and J. Solbes, Enseñanza de las ciências 5, 209 (1987).

[5] F. Ostermann and C.J.H. Cavalcanti, Caderno Catarinense de Ensino de Física 16, 267 (1999).

[6] G. Brockington, A Realidade escondida: a dualidade ondapartícula para estudantes do Ensino Médio. Dissertação de Mestrado, Universidade de São Paulo, São Paulo (2005).

[7] J. Nicolau, Estrutura Didática Baseada no Fluxo: Relatividade Especial para o Ensino Médio. Dissertação de Mestrado, Universidade de São Paulo, São Paulo (2014).

[8] I. Lawall, M. Pietrocola, E. Ricardo, G. Shinomiya and M. Siqueira, Dificuldades de professores em Física em situação de Inovações Curriculares e em Curso de Formação (XII EPEF, Águas de Lindóia, 2010).

[9] M. Pietrocola, E. Ricardo, M. Siqueira and I. Lawal, in Esera Conference proceedings (Istambul, ESERA, 2009)

[10] M. Siqueira, Do Visivel ao Indivisivel: uma proposta de Física de Partículas Elementares para o Ensino Médio. Dissertação de Mestrado, Universidade de São Paulo, São Paulo (2006).

[11] Y. Chevallard, La Transposicion Didactica: Del saber sabio al saber enseñado (La Pensée Sauvage, Buenos Aires, 1991).

[12] A. Brown, The Journal of the Learning Science 2, 141 (1992).

[13] A. Collins, in: New directions in educational technology, edited by E. Scanlon and T. O'Shea (Springer-Verlag, Berlin, 1992).

[14] R.C. Richey, J.D. Klein and W.A. Nelson, in: Handbook of research on educational communications and technology, edited by D.H. Jonassen (Routledge, London, 2004).

[15] DBR Collective, Educational Researcher 32, 5 (2003).

[16] J. Van den Akker, in: The Design methodology and developmental research in education and training, edited by J. Van den Akker, N. Nieveen, R.M. Branch, K.L. Gustafson and T. Plomp (Kluwer Academic Publishers, Norwell, 1999).

[17] F.B. Kneubil and M.A. Pietrocola, in: Crossing the Border of the Traditional Science Curriculum, edited by M Pietrocola and I. Gurgel (Sense Publishers, Netherlands, 2017).

[18] P. Lijnse and K. Klaassen, International Journal of Science Education 26, 537 (2004). 
[19] M. Méheut and D. Psillos, International Journal of Science Education 26, 515 (2004).

[20] A. Tiberghien, in Improving Science Education - The Contribution of Research, edited by R. Millar, J. Leach and J. Osborne (Open University Press, Buckingham, 2000).

[21] F.B. Kneubil and M. Pietrocola, Investigações em Ensino de Ciências 22, 01 (2017).

[22] F.B. Kneubil, European Journal of Physics 37, 065201 (2016).

[23] T. Kuhn, The Structure of Scientific Revolutions (The University of Chicago Press, Chicago, 1962), $2^{\mathrm{a}}$ ed.

[24] F.B. Kneubil, Revista Brasileira de Ensino de Física 40, e4305 (2018).

[25] I. Arriassecq and I.M. Greca, Science \& Education 21, $827(2012)$

[26] C. Buty and J.F. Tiberguien, International Journal of Science Education 26, 579 (2004).

[27] M. Méheut, International Journal of Science Education 26, 605 (2004).

[28] D. Psillos, V. Tselfes and P. Kariotoglou, International Journal of Science Education 26, 555 (2004).

[29] F. Kabapinar, J. Leach and P. Scott, International Journal of Science Education 26, 635 (2004).

[30] M. Komorek, and R. Duit, International Journal of Science Education 26, 619 (2004).

[31] M.I. Hernández and R. Pintó, Desenvolupament iteratiu d'una seqüència d'ensenyament $i$ aprenentatge sobre Propietats Acústiques dels Materials. Doctoral Thesis, Universitat Autònoma of Barcelona, Barcelona (2012).

[32] K. Davis, Science Education 87, 3 (2003).

[33] R. Pintó, International Journal of Science Education 89, 38 (2005).

[34] P. Perrenoud, Práticas pedagógicas, profissão docente e formação. Perspectivas Sociológicas (Dom Quixote, Lisboa, 1993).

[35] C. Gauthier, Por uma teoria da Pedagogia: pesquisas contemporâneas sobre o saber docente (Unijuí, Ijuí, 1998).

[36] P. Meurieu, Aprender...sim, mas como? (Artes Médicas, Porto Alegre, 1998), $7^{\mathrm{a}} \mathrm{ed.}$

[37] M. Tardif, Saberes Docentes e Formação Profissional (Vozes, Petrópolis, 2012).

[38] L. S. Shulman, Educational Researcher 15, 4 (1986).

[39] A.N.S. Triviños, Introdução à Pesquisa em Ciências Sociais: a pesquisa qualitativa em educação (Atlas, São Paulo, 2009).

[40] F.B. Kneubil and M.R. Robilotta, Science \& Education 24, 645 (2015).

[41] R.A.S. Karam, Physical Review Special Topics on Physics Education Research 10, 010119 (2014).

[42] I. Koponen and M. Pehkonen, in: Proccedings of $3 \mathrm{rd}$ International Conference on Concept Mapping (Tallinn University, Tallinn, 2008).

[43] O. Uhden, R. Karam, M. Pietrocola and P. Gesche, Science \& Education 21, 485 (2012).

[44] G. Bachelard, A Filosofia do Não: Filosofia do Novo Espírito Científico (Abril Cultural, São Paulo, 1978).

[45] E. Garrido and A.M. Carvalho, Cadernos de Pesquisa 107, 149 (1999).

[46] M.R. Siqueira, Professores de física em contexto de inovação curricular: saberes docentes e superação de obstáculos didáticos no ensino de física moderna e contem- porânea. Tese de Doutorado, Universidade de São Paulo, São Paulo (2012). 